\title{
REVIEW
}

\section{OSTEOPOROSIS: THERAPEUTIC OPTIONS}

Stefka Ivanova ${ }^{1}$, Liliya Vasileva $^{2 *}$, Stanislava Ivanova ${ }^{3}$, Lily Peikova $^{1}$, Danka Obreshkova $^{3}$

${ }^{1}$ Department of Pharmaceutical Chemistry, Faculty of Pharmacy, Medical University Sofia, Bulgaria,

${ }^{2}$ Department of Pharmacology and Clinical Pharmacology, Faculty of Pharmacy, Medical University

Plovdiv, Bulgaria, ${ }^{3}$ Department of Pharmacognosy and Pharmaceutical Chemistry, Faculty of Pharmacy, Medical University Plovdiv, Bulgaria

\section{ОСТЕОПОРОЗ: ТЕРАПЕВТИЧЕСКИЕ ВОЗМОЖНОСТИ}

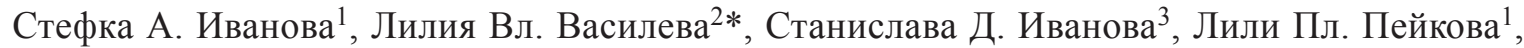
Данка П. Обрешкова ${ }^{3}$

${ }^{1}$ Кафедра фармачевтической химии, Медииинский университет, София, Болгария, ${ }^{2}$ Кафедра фармакологии и клинической фармакологии, Факультет медицины, Медицинский университет, Пловдив, Болгария, ${ }^{3}$ Кафедра фармакогнозии и фармацевтической химии, Факультет фармации, Медищинский университет Пловдив, Болгария

\begin{abstract}
The definition of osteoporosis was originally formulated at a conference of the World Health Organization (WHO) in 1993 as 'a systemic skeletal disease characterized by decreased bone mass and altered micro-architecture of bone tissue, leading to enhanced bone fragility and risk of fractures'. Osteoporosis is characterized by low bone mineral density (BMD) and loss of the structural and bio-mechanical properties that are required to maintain bone homeostasis. This review aims to address the currently available options in prevention and treatment of osteoporosis. Management of osteoporosis includes non-pharmacological treatment - diet rich of calcium and vitamin D, healthy lifestyle, proper exercise plan, and pharmacological therapy. Combination of non-pharmacological and pharmacological treatment options have to be considered for prevention of osteoporosis and minimization of the risk of fractures. Given the heterogeneity of osteoporosis syndrome and lack of significant number of comparative studies, the choice of a pharmacological agents should be individualized.
\end{abstract}

Key words: osteoporosis, treatment, prevention, pharmacology, structure-activity

Folia Medica 2015;57(3\&4):181-190

Copyright (C) 2015 Medical University, Plovdiv

\section{РЕЗЮМЕ}

Определение остеопороза первоначально сформулировано на конференции Всемирной организации здравоохранения (ВОЗ) в 1993 г. как: „,системное заболевание скелета, которое характеризуется снижением костной массы, нарушением микроархитектоники костнойткани, усилением хрупкости кости иповышением риска переломов". Остеопороз характеризуется снижением плотности костей (bone mineral density - BMD) и потерей структурных и биохимических свойств, необходимых для поддерживания гомеостаза костей. Целью настоящего обзора является выяснение наличных на данный момент возможностей профилактики и лечения остеопороза. Терапия остеопороза включает нефармакологические методы - диета, обеспечивающая поступление в организм кальция и витамина Д, здоровый образ жизни, подходящий режим физических нагрузок, а также фармакологическую терапию. Комбинация нефармакологических и фармакологических методов терапии должна быть тщательно продуманной с целью профилактики остеопороза и понижения риска переломов. Учитывая гетерогенность синдрома остеопороза и отсутствие значительного количества сравнительных исследований, выбор фармакологических агентов должен быть строго индивидуализирован.

Ключевые слова: остеопороз, терапия, профилактика, фармакология, структура-активность

Folia Medica 2015;57(3\&4):181-190

(C) 2015 Все права защищены. Медицинский университет, Пловдив

\section{INTRODUCTION}

The definition of osteoporosis was originally formulated at a conference of the World Health Organization (WHO) in 1993 as a systemic skeletal disease characterized by decreased bone mass and altered microarchitecture of bone tissue ${ }^{1}$, leading to enhanced bone fragility and risk of fractures'. ${ }^{2}$ Osteoporosis is characterized by low bone mineral

Article's history: Received: 29 Oct 2015; Received in a revised form: 5 Jan 2016; Accepted: 7 Jan 2016

*Correspondence and reprint request to: L. Vasileva, Department of Pharmacology and Clinical Pharmacology, Medical Faculty, Medical University, Plovdiv; E-mail: vasileva.1.v1@gmail.com; Tel: +359899514 113 
density (BMD) and loss of the structural and biomechanical properties that are required to maintain bone homeostasis. In 2001, at a conference of the American Institute of Health osteoporosis was defined as „bone damage, characterized by compromised bone strength (bone density and quality of bone tissue), predisposing the individual to an increased risk of fractures occurring spontaneously or after minor injuries. Fractures due to bone fragility result from osteoporosis, affecting most often the spine, hip and forearm. ${ }^{3}$ The imbalance between the activity of osteoblast and osteoclast is the major cause of osteoporosis. $^{4}$

\section{CLASSIFICATION OF TYPES OF OSTEOPOROSIS}

Osteoporosis can be primary and secondary.

Primary osteoporosis: 1) postmenopausal (type $1)^{5}$ - is typical for women between 45 and 65 , due mainly to the loss of ovarian function and estrogen deficiency and mainly affecting the vertebral bodies - trabecular bone ${ }^{6} ; 2$ ) senile (type 2) - in women over 70-75, and is pre-determined by decreased intake of calcium and vitamin D, decreased intestinal absorption, reduced production and metabolism of vitamin $\mathrm{D}$ in the body and the aging process; 3 ) idiopathic (juvenile) fractures - a rare form: for individuals in fertile age (under 40$)^{7}$.

Secondary osteoporosis is induced by diseases or medications affecting bone tissue ${ }^{8}$. Long-term administration of glucocorticoids, proton pump inhibitors, selective serotonin receptor inhibitors, androgen deprivation therapy, thiazolidinedione, heparin, calcineurin inhibitors, and some chemotherapies such as methotrexate have deleterious effects on bone health. ${ }^{8,9}$ An important secondary type is a glucocorticoid-induced osteoporosis, which develops very quickly. ${ }^{10}$ The degree of bone loss $10-40 \%$ occurs during the first year of corticosteroids therapy. Risk factors are: high cumulative dose and prolonged duration of glucocorticoid therapy; age above 50 years, postmenopausal status, diseases accompanied by increased production of interleukin 1 (IL-1), interleukin 6 (IL-6), tumor necrosis factor a (TNF- $\alpha$ ) (rheumatoid arthritis). ${ }^{8}$ Osteoporosis occurs in $50 \%$ of patients treated with glucocorticoids for more than 6 months and fractures occur in $1 / 3$ of patients within the first 6 to 12 months. ${ }^{11}$ The mechanisms of corticosteroids affecting the bone health are: 1) reducing the intestinal absorption of calcium which leads to increased bone resorption; 2) directly inhibiting osteoblasts function by: suppression of growth factors: BMP-2 (bone morphogenetic protein-2) and 1-C bf $\alpha$ (binding factor $\alpha 1$ ), reduction of IGFs (insulin-like growth factor), inhibition of proliferation and differentiation of pre-osteoblasts, promoting their differentiation to adipocytes and potentiation of apoptosis of mature osteoblasts and osteocytes; 3) directly stimulating bone resorption; 4) decreased circulating levels of sex hormones and may cause necrosis of the hip ${ }^{10,11}$.

\section{EPIDEMIOLOGY}

Osteoporosis is estimated to affect 200 million people and in 2000 it was designated as the third socially significant diseases in the world (after cardiovascular and oncological diseases), forecast to take second place by $2020 .^{3}$ Due to its high prevalence throughout the world, it is considered a major risk factor for public health. Bone resorption is a natural phenomenon and can occur due to old age. ${ }^{12}$ Osteoporosis affects men and women of any age, more commonly postmenopausal women ${ }^{12-14}$ and women over 50 years of age ${ }^{5}$. Osteoporosis is more common in women than in men: $50 \%$ of women ${ }^{14}$ and $25 \%$ of men aged over 50 have osteoporotic fractures ${ }^{15}$. The risk of fracture increases steadily with age in both sexes and is associated with reduced bone mineral density. ${ }^{16}$ After 50 years of age one in three women and one in five men can get at least one fracture due to bone fragility. ${ }^{17}$ The risk of fractures in women aged over 50 is $53.2 \%$ and for men is $20.7 \% .^{18}$ The risk after 50 for women $(53.2 \%)$ is greater than the corresponding risk of endometrial carcinoma (2.6\%), breast cancer $(10 \%)$, stroke $(20 \%)$, and coronary heart disease $(46 \%){ }^{16}$

\section{ETIOLOGY}

Risk factors for the disease are controllable and uncontrollable ${ }^{16}$.

Uncontrollable factors include: age over 65 years, sex, race, genetic factors, familial predisposition, previous fractures, insufficient bone growth, oxidative stress, premature menopause, diseases, medications. ${ }^{12,16,18}$ Diseases that are a risk factor for secondary osteoporosis are: 1) gastrointestinal: gastrectomy, inflammatory bowel disease, colitis, gastric bypass, eating disorders; 2) endocrine: acromegaly, diabetes, thyrotoxicosis, Cushing syndrome, hyperparathyroidism, hypogonadism; 3) hematologic disorders: leukemia, lymphoma, multiple myeloma, sickle cell anemia, thalassemia, hemophilia; 4) other diseases: ankylosing spondylitis, asthma, renal insufficiency, spinal damage, stroke, ischemic heart disease, systemic lupus erythematosus, induced menopause, multiple sclerosis, Alzheimer`s disease, Parkinson`s, prostate cancer, rheumatoid arthritis, 
AIDS, organ transplantation, and liver failure. Medications that cause osteoporosis by reducing the ability of bone to be recovered are: antidepressants, anticonvulsants, antihypertensives, glucocorticoids, diuretics, immunosuppressants, sedatives, tranquilizers, hypoglycemic agents, chemotherapeuticals against excess thyroid hormones. ${ }^{8-11}$ Controllable risk factors for osteoporosis are: $\operatorname{diet}^{12,16,19}$, low bone mineral density, deficiency in the intake of calcium, magnesium, vitamin $\mathrm{D}^{20,21}$; low body mass index (BMI $20 \mathrm{~kg} / \mathrm{m}^{2}$ leads to an increased risk of fractures -2 times higher, and $16 \mathrm{~kg} / \mathrm{m}^{2}-4$ times) ${ }^{12}$; excessive use of alcohol ${ }^{22}$, caffeine $^{23}$, sodium, smoking ${ }^{24}$; environmental pollutants and heavy metals; lack of physical activity $^{25-28}$. Vitamins B6, C and $\mathrm{K}$ are important for the synthesis of bone proteins. ${ }^{20}$ Magnesium enhances calcium absorption and transport. Zinc stimulates bone formation and inhibits bone loss. Strontium promotes differentiation of osteoblasts and helps to balance the activity of osteoclasts and osteoblasts. ${ }^{3}$ High intake of caffeine, salt, and soda is associated with bone loss and osteoporotic fractures, due to an increased excretion of calcium in urine. ${ }^{23}$ Chronic alcohol consumption decreases bone mass and increases the risk of fractures, slowing the proliferation and activity of osteoblasts, lowers serum osteocalcin, leads to hypogonadism, metabolic acidosis, liver disease and hypovitaminosis $\mathrm{D}$, pseudo-Cushing syndrome with hipercortisolemia. ${ }^{22}$ Smoking is connected by 1.25 -fold increased total fracture risk, reduced intestinal absorption of calcium and increased metabolism of endogenous and exogenous estrogens to inactive derivatives. ${ }^{25}$

Recent studies suggest potential role of physical exercises in prevention and management of osteoporosis. ${ }^{25-28}$ Weight-lifting exercise is associated with increases in bone density. Krasnova et al report that regular sport activities provided good prophylaxis for osteoporosis within women. ${ }^{25}$

\section{PATHOGENESIS}

Osteoporosis is a result of an imbalance between the activity of osteoblast and osteoclasts. ${ }^{1,2,29}$ The imbalance between bone resorption and formation is attributed to extension of the life of the osteoclasts and shortening of the life of osteoblasts. ${ }^{30}$ Remodeling of the bone in order to maintain optimal endurance consists of 4 cycles lasting several months. In the resting phase stem cells from the bone marrow migrate to the bone surface and the osteoclasts differentiate, which, during the phase of resorption creates a low $\mathrm{pH}$ and proteolytic enzymes are produced. During the recovery phase osteoclasts degrade the bone wound and on the bone surface attracts mesenchymal stem cells, which are transformed into osteoblasts. In the formation phase the osteoblasts form new bone through the deposition of protein matrix (osteoid consisting of collagen type I), which is mineralized. . $^{2,30}$

The activity of osteoblasts and osteoclast is under the influence of many regulating factors sex hormones - mainly estrogens, glucocorticoids, parathormone, calcitonin, vitamin D, RANKL. ${ }^{1,4,7}$

During menopause, the rate of bone resorption is sharply increased. This increased activity of osteoblasts and osteoclasts is mainly associated with estradiol deficiency and an increased concentration of glucocorticoids. ${ }^{29}$ The loss of sexual hormones regulate osteoclast formation and bone marrow osteoblasts by influencing the production of interleukin 1 (IL-1), interleukin 6 (IL-6), tumor necrosis factor $\alpha(\mathrm{TNF} \alpha)$ and macrophage colony stimulating factor (M-CSF), which mediate the genesis of osteoclasts and osteoblasts. ${ }^{31,32}$ Osteoblast differentiation factors requires alkaline phosphatase, osteocalcin, and osteopretegrin transcription factor 2. Adipocytes are secretory cells of the bone marrow stroma that affect the osteogenesis by interfering with the osteoblast proliferation, differentiation and mineralization and enhance osteoclast formation ${ }^{29}$. Free radicals are responsible for the induction of apoptosis and inhibition of osteoblast genesis and activation of osteoclasts differentiation. Therefore, application of antioxidants may have a beneficial effect on bone tissue. ${ }^{33}$ The main cause of osteoporosis in women is reduced levels of estrogen, which in postmenopausal women are one-tenth of the levels in premenopausal women. The reduced levels of estrogen leads to: 1 ) increase of oxidative stress; 2) apoptosis of osteoblasts; 3) rapid loss of bone mass due to an increased rate of degradation of the bone tissue by osteoclasts. ${ }^{34}$

\section{DIAGNOSIS OF OSTEOPOROSIS}

According to the requirements of the World Health Organization from 1994 diagnosis of osteoporosis is based on the measurement of bone mineral density (BMD), which is a quantitative criterion, reflecting the contribution of bone changes to the overall fracture risk and a comparison of BMD of patients with the BMD of healthy young adult (between 20 and 40 years of age) of the same sex and race. ${ }^{31}$ Determination of "T-score" represents the number of standard deviations (SD) above or below the mean BMD for the healthy young population. WHO 
and the International Foundation for Osteoporosis defined diagnostic categories: 1) healthy subjects: $\mathrm{T}>1 \mathrm{SD} ; 2$ ) reduced BMD (osteopenia) $>2.5$ and $\leq 1 \mathrm{SD} ; 3$ ) osteoporosis: $\leq 2.5 \mathrm{SD} ; 4$ ) aggravated osteoporosis - in postmenopausal women and men over 50 with fractures of the hip, spine or forearm..$^{32}$

However, BMD alone has a limited value to predict the risk of fractures. The incidence of osteoporotic fractures increases with age. The predictive value of BMD becomes weaker with age. It has become evident that fracture risk is also driven by parameters including bone size and shape, bone turnover, micro-architecture, damage accumulation (micro cracks), and degree of mineralisation or collagen structure, all playing a role in bone strength, and hence in the risk of osteoporotic fractures. Several epidemiological studies showed that a large proportion of incident fragility fractures occur in postmenopausal women who have a BMD T-score above -2.5. The use of bone-related independent risk factors for fractures combined with BMD values provides a global assessment of future fracture risk, allowing the identification of women who should benefit from a treatment to prevent the occurrence of osteoporotic fractures.

The range of tests for the diagnosis of osteoporosis depends on the severity of the disease, age, presence or absence of fractures. The application of various techniques for diagnosis helps in prediction of fracture risk, tracking of age-related changes in BMD and treatment. ${ }^{31,32}$

\section{TREATMENT OF OSTEOPOROSIS}

Goals of treatment are to reduce the incidence of new fractures and influence of risk factors. Most pharmacological agents used in the prevention and treatment of osteoporosis reduce bone resorption or delay the total rate of bone turnover.

\section{INHIBITORS OF BONE RESORPTION}

Bone resorption could be inhibited by: 1) reducing the formation of osteoclasts; 2) inhibition of the activity of mature osteoclasts; 3 ) induction of apoptosis of osteoclasts. The maturation of osteoclasts slows down as a results from intake of calcium, vitamin D, bisphosphonates, inhibitors of RANKL (denosumab), estrogens, selective estrogen receptor modulators (SERM). ${ }^{1,4,5}$. Inhibitors of the activity of mature osteoclasts are: bisphosphonates, calcitonin, cathepsin K, the protease inhibitor odanacatib. Stimulators of apoptosis of osteoclasts are bisphosphonates and calcitonin.

\section{CALCIUM AND VITAmin D}

Fundamental principle in the prevention of osteoporosis is a change in lifestyle to reduce the impact of modifiable risk factors and enhance protective factors: nutrition and physical activity ${ }^{25-28}$. Adequate intake of inhibitors of bone resorption such as calcium, Vitamin D and combination of them is essential for preventing osteoporosis and is an essential addition to the preventive therapy ${ }^{35}$. Deficiency of calcium reduces bone strength and increases susceptibility to fractures ${ }^{4}$. Low intake of calcium occurs with aging or in young individuals with eating disorders. The intestinal calcium absorption is decreased in patients with gastrointestinal disorders (gastrectomy, gastric bypass, pernicious anemia eating disorders), and in the elderly. ${ }^{35}$ The recommended calcium intake with food is: a) 4-8 years - $800 \mathrm{mg} /$ day; b) 9-18 years - 1300 $\mathrm{mg} /$ day; c) pre-menopausal women - $1000 \mathrm{mg}$ / day; d) men after teenage and until the age of 50 - $1000 \mathrm{mg} /$ day; e) menopausal women: 1500 $\mathrm{mg} /$ day; f) men over the age of $50-1500 \mathrm{mg} /$ day; g) during pregnancy and lactation $-1000 \mathrm{mg}$ / day. Calcium intake up to $2500 \mathrm{mg} /$ day do no increases the risk for the occurrence of hypercalciuria or nephrolithiasis. Individuals with impaired kidney function should avoid excessive intake of calcium (over $2500 \mathrm{mg} /$ day). ${ }^{35}$ Hypovitaminosis D is a result from the low dietary intake, low exposure to sunlight, increased pigmentation of the skin, liver disease, obesity, or use of drugs which affect the metabolism of vitamin D, as anticonvulsants. ${ }^{36,37}$ Vitamin D increases bone mineral density and reduces fractures, especially when combined with an adequate intake of calcium. ${ }^{35}$ Vitamin D3 at a daily dose of $800 \mathrm{IU}$ with calcium $(1000 \mathrm{mg})$ reduces the risk fractures in elderly. 2,4,12,35-37

The recommended daily intake of vitamin D from food and supplements together: a) men and women in, $65-\geq 600 \mathrm{IU}(15 \mu \mathrm{g})$ per day; b) men and women over 65 years of age: $\geq 800 \mathrm{IU}(20 \mu \mathrm{g})$ per day; in men and women with proven deficit and during pregnancy 2000-4000 IU (50-100 $\mu \mathrm{g})$ per day. All patients with osteoporosis undergoing anti-osteoporosis treatment, must receive a minimum of $800 \mathrm{IU}$ of vitamin D per day, in order to ensure an optimal effect of the treatment. At doses of 700-1000 IU improves muscle strength and reduces fractures. ${ }^{37}$

\section{BisPHOSPHONATES}

Bisphosphonates are synthetic pyrophosphate derivatives which contain a carbon atom instead 
Table 1. Bisphosphonates

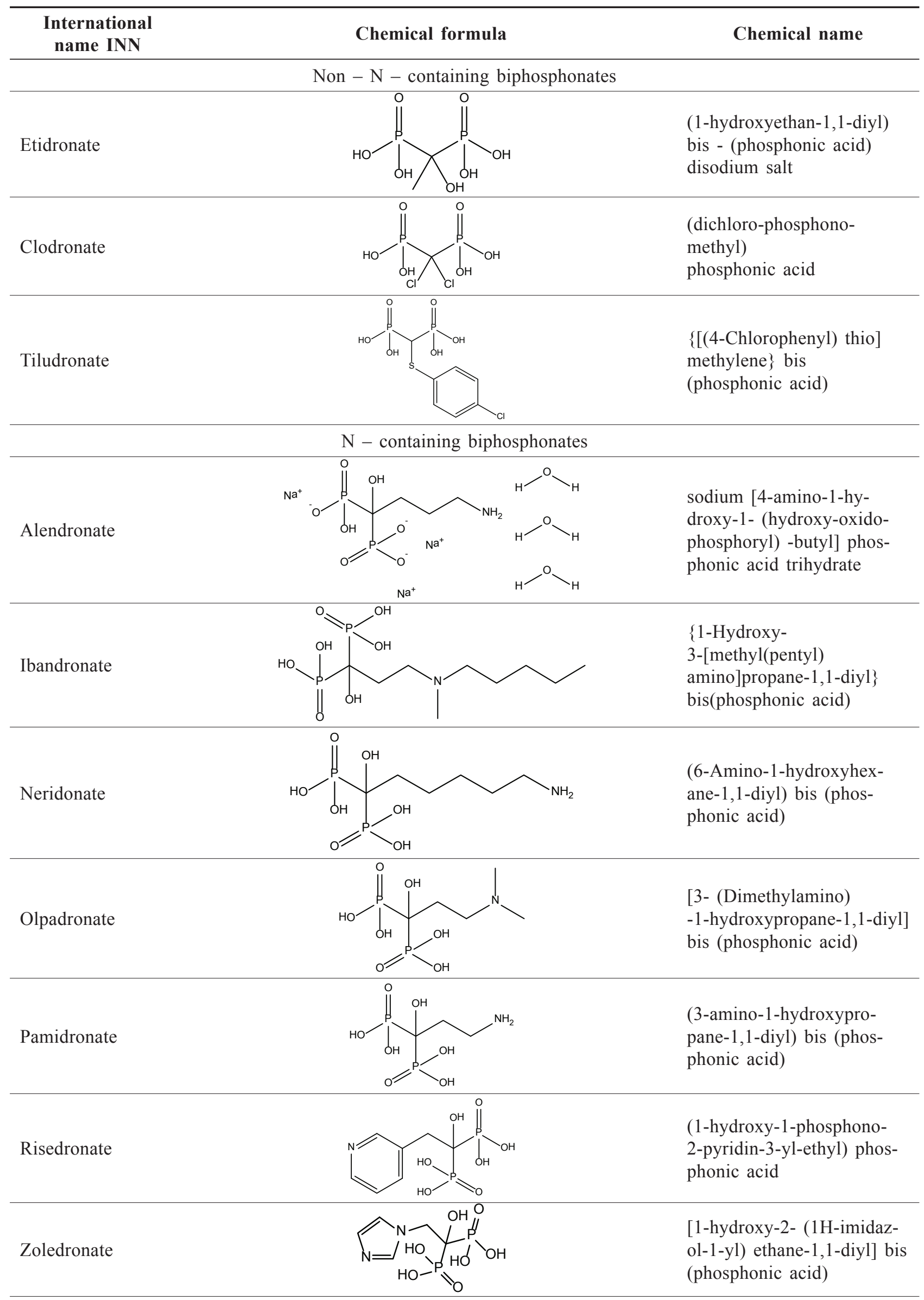


of an oxygen atom. P-C-P bond enhances the sustainability of enzymatic and chemical hydrolysis. The mechanism of action of bisphosphonates on bone is complex and involves a decrease in the production and activity of osteoclasts, increasing osteoclast apoptosis, resulting in specific inhibition of farnesyl pyrophosphate synthase, an enzyme that regulates the biosynthesis of mevalonate, cholesterol, and regulatory proteins (rab, rho , rac), that mediate osteoclast activity. ${ }^{38}$ Bisphosphonates are used to treat metabolic bone diseases characterized by increased bone resorption: osteoporosis, Paget's disease and myeloma. ${ }^{1,4} \mathrm{Bi}$ phosphonates have been conclusively shown to increase bone density and reduce fractures over at least 5 years when used continuously. ${ }^{5-7}$ Bisphosphonates inhibit bone resorption through their influence on the osteoclasts and decrease the risk of vertebral and non-vertebral fracture. In patients over 60-65 years of age combined intake with vitamin $\mathrm{D}$ and calcium preparations is required. Alendronate, and zolendronate are applied in glucocorticoid-induced osteoporosis. ${ }^{38}$

There are two classes of bisphosphonates: the $\underline{\mathrm{N}}$-containing and non-N-containing bisphosphonates. The differences in the chemical structures of the two classes represent the differences in their mechanism of action. Non-N-bisphosphonates: etidronate, clodrante, tiludronate (Table 1) are metabolized in the cell to compounds which replace part of the terminal pyrophosphate adenosine triphosphate (ATP) to form non-functional molecules that compete with ATP. The N-containing bisphosphonates: neridronate, pamidronate, olpadronate, alendronate, ibandronate, risedronate, zoledronate (Table 1) are acting on bone metabolism by binding to and blocking the enzyme farnesyl diphosphate synthase (FPP) in the path of the HMG-CoA (mevalonate pathway) resulting in preventing the formation of farnesol. ${ }^{39,40}$ Through clinical trials, efficacy was demonstrated against fractures of ibandronate (MOBILE, VIBE), risedronate (VERT), zoledronate (HORIZON). Bisphosphonates efficacy in inhibiting bone resorption is significant. Connecting degree of non-containing $\mathrm{N}$ is: tiludronate $>$ clodronate $>$ etidronate, and of $\mathrm{N}$-containing is: zoledronate $>$ alendronate $>$ ibandronate $>$ risedronate ${ }^{39}$. Bonding extent explains the duration of action of zoledronate and alendronate in comparison with the more readily reversible effects of risedronate. ${ }^{39,40}$

INHIBITORS OF RANK-LIGAND

Anti-resorptive agent denosumab is a human mono- clonal antibody, which is administered subcutaneously at a dose of $60 \mathrm{mg} 1$ time per 6 months. This agent blocks the RANK/RANKL/OPG system, which is responsible for osteoclastic activation, thus reducing bone resorption. ${ }^{41}$ Naturally RANKL is molecule produced by osteoblasts. It stimulates osteoclastogenesis via RANK, the receptor for RANKL that is present on osteoclasts. Denosumab inhibits osteoclast formation and activity. ${ }^{1,2,4}$ It is at least as effective as the potent bisphosphonates in inhibiting bone resorption and has recently been approved for treatment of postmenopausal osteoporosis and some cancers (prostate and breast). The latter application is to limit the development of bone metastases or bone loss resulting from the use of drugs suppressing gonadal function. Denosumab is administered subcutaneously every 6 months, which avoids gastrointestinal side effects. The drug appears to be well tolerated. In the FREEDOM study has been found that the drug reduces vertebral fractures by $68 \%$, non-vertebral $-20 \%$, femoral $-40 \%$. In studies, DECIDE and STAND demonstrate that denosumab increases bone density stronger than alendronate. ${ }^{41}$

\section{HORMONE REPLACEMENT THERAPY (HRT)}

The term „hormone replacement therapy“ (HRT) is used to indicate the common use of estrogen and progestin in postmenopausal women. Until 2002 HRT has been seen as a first line therapy for the prevention and treatment of postmenopausal osteoporosis. ${ }^{42}$ Hormone replacement therapy has beneficial effects on vertebral and non-vertebral fractures, but is not recommended as a primary indication for prevention and treatment of osteoporosis due to unfavorable risk / benefit ratio in accordance with data from the Women's Health Initiative Study indicating increased risk of heart attack, stroke and breast cancer. ${ }^{43}$ Hormone replacement therapy is allowed up to 3 years and at the lowest therapeutic dose (mainly as skin patches) when the expression of heavy menopausal symptoms and osteoporosis is combined. ${ }^{43,44}$ Hormonal therapy reduces the risk of osteoporotic fractures, improves bone mineral density (BMD), suppresses biochemical markers of bone resorption, and reduces the loss of bone mass. ${ }^{1,3,4,42}$ The mechanism of action of estrogens differs from that of bisphosphonates. The combination of these two groups of agents has additive effects on the reduction of bone resorption markers and BMD. ${ }^{43,44}$ Estradiol is an agonist of nuclear steroid estrogen (ER) receptors: ER $\alpha$ and ER $\beta$ and intracellular membrane non-nuclear estrogen receptor GPER 
and inhibits bone resorption. ${ }^{42}$ In osteoporosis Estradiol could be administered also transdermally. ${ }^{1,4,5}$ Progestins with stronger androgenic and weaker glucocorticoid effect (noresthisterone acetate) prevents bone loss in higher degree compared to progestins with weaker androgenic and stronger glucocorticoid action. ${ }^{43}$

The synthetic steroid tibolone has weak estrogenic, progestogenic and androgenic properties and prevent postmenopausal bone loss. ${ }^{44}$ In LIFT clinical study was found that tibolone significantly reduces vertebral and non-vertebral fractures. ${ }^{44}$ Effects of testosterone is effected by the activation of androgen receptors, and by conversion into estradiol. In males with hypogonadism treated with depo-testosterone $200 \mathrm{mg}$ intramuscular injection bone resorption is reduced. ${ }^{45}$ Anabolic steroids are analogs of Testosteron: $17-\beta$-esterified derivatives - Nandrolone is administered parenterally, and 17 - $\alpha$-methylated steroids - danazol, oxandrolone, stanozolol - orally. Anabolic steroids reduce the risk of fracture by: 1) improving calcium balance; 2 ) increasing the number of the osteoblasts' precursors and stimulate their differentiation into mature osteoblasts; 4) increase in the bone mineral density and recovery of skeletal microarchitecture; 5) inhibition of bone resorption. ${ }^{45}$

\section{CALCitonin}

Calcitonin is a peptide hormone produced by the $\mathrm{C}$ cells of the thyroid gland. A disulfide bond between positions 1 and 7 is essential for biologic activity. Calcitonin derived from fish has more potent antiresorptive effect than the human recombinant one and reduces bone resorption by inhibiting osteoclast activity and bone mass increase. In the study Prevent Recurrence of Osteoporotic Fractures (PROOF) was shown that a daily dose of 200 IU recombinant salmon nasal-calcitonin reduces vertebral fractures by $36 \%$. Since July 2012, the European Medicines Agency (EMA) does not recommend its use for the treatment of osteoporosis due to increased frequency of certain types of cancers in the study PROOF. ${ }^{46} \mathrm{It}$ has been shown to increase bone mass and reduce fractures, but only in the spine. It does not appear to be as effective as bisphosphonates or teriparatide.

\section{Selective estrogen Receptor modulators (SERM)}

Selective estrogen receptor modulators (SERMs) have been developed to retain the beneficial effects of estrogens on bone while minimizing deleterious effects on breast, uterus, and the cardiovascular system. Tamoxifen was the first SERM to be widely used in clinical practice, based on its now well- recognized estrogen antagonist activity in the breast. The prolonged use of tamoxifen was associated with an increase in uterine cancer, leading to the search for other SERMs with different pharmacological profiles. ${ }^{1,4,5}$ Thus raloxifene, bazedoxifene, lasofoxifene and arzoxifene, new SERMs, were developed for the treatment and prevention of postmenopausal osteoporosis, with the goal of improving the drug safety profile. Raloxifene has a spectrum of tissue-specific agonist-antagonist effects on estrogen target tissues but acts on bone as an estrogen agonist. This drug has been extensively studied and data support its estrogen agonist profile in the skeletal system. ${ }^{47}$ The molecular mechanisms of action of SERM include: 1) differential binding activity to ER- $\alpha$ receptors (selective partial agonist / antagonist) and ER- $\beta$ receptors (selective antagonist); 2) direct reduction of resorbing activity by inhibiting the production of interleukin 6, tumor necrosis factor $\alpha$ and inhibition of RANKL and increased production of transforming growth factor - $\beta 3 .{ }^{47}$ SERM are shown for the prevention of vertebral fractures and treatment of osteoporosis in postmenopausal women. ${ }^{47}$

\section{Phytoestrogens}

Phytoestrogens are polyphenolic plant metabolites: flavonoids, flavonols: kaempferol, quercetin, rutin, icariin; flavanols: catechin, epicatechin of Camellia sinensis L.; polymeric flavanols proanthocyanidins; flavanones: hesperidin; isoflavones: daidzein, genistein, glycitein, kalita formononetin, biochanin A and coumestans, coumestrol, 4'-O-methylcoumestrol; isoflavones: equiol; polyphenols: oleuropein, oleocanthin; lignans: enterolactone, enterodiol; stilbenes: resveratrol. ${ }^{48}$ Phytoestrogens possess estrogenic activity and show a higher affinity for $\beta$-estrogen receptor, due to structural similarity with $17 \beta$-oestradiol stimulate osteoblast differentiation and inhibiting osteoclastogenesis. Rutin inhibits osteoclast formation by reducing the free radicals and the levels of TNF- $\alpha .{ }^{48}$ Isoflavones reduce the number of osteoclasts leads to restoring the balance between bone formation and resorption. Formononetin of Trifolium pratense antioxidant preventing bone resorption due to an increase in the activity of superoxide dismutase, catalase and glutathione peroxidase. Coumestrol increased alkaline phosphatase, type I collagen and osteocalcin activity and prevent bone resorption. Polyphenols such as oleuropein and oleocanthin stimulate osteoblasts and inhibit osteoclast formation. Lignan precursors lariciresinol, matairesinol, pinoresinol and secoisolariciresinol under the action 
of intestinal bacteria transformed into substances with estrogenic activity and antioxidant effects: Matairesinol - in enterolactone, secoisolariciresinol - in enterodiol. Isotaxiresinol is lignan isolated from Taxus yunnanensis L. also inhibits bone resorption. ${ }^{48}$

\section{BONE-BUILDING DRUGS}

HUMAN RECOMBINANT PARATHYROID HORMONE

Stimulators of bone formation are parathyroid hormone (PTH 1-84), Teriparatide (1-34), antagonists of the calcium-sensing receptors in the parathyroid gland (stimulate endogenous PTH secretion). The effects of PTH on bone vary greatly depending on the dose. At high levels of PTH (1-84) exhibits catabolic effect and primary hyperparathyroidism and fractures. Administration of low doses of PTH (1-84) or a fragment 1-34 (teraparatide) has an anabolic effect and stimulate bone formation by activation of the production of insulin-like factor 1, which facilitates the differentiation to osteoblasts and protects osteoblasts from apoptosis. PTH increases bone mineral content at the spine in men and women with glucocorticoid-induced osteoporosis. ${ }^{49}$ PTH (1-84) in daily subcutaneous injection of $100 \mu \mathrm{g}$ is effective in preventing a vertebral fracture (reduction of $40-50 \%$ ) in postmenopausal women with severe osteoporosis. ${ }^{49}$ Due to the strong stimulating effect on the osteoblasts teriparatide $20 \mu \mathrm{g}$ subcutaneous is registered for use up to 18-24 months in: 1) men and women over 65 years with $\mathrm{T}$-score $\leq-2.5 \mathrm{SD}$, as a first line treatment alternative to bisphosphonates; 2) prevention of vertebral and non-vertebral fractures in postmenopausal women with low mineral density in severe osteoporosis T-score $\leq-3.5 \mathrm{SD}$ and multiple vertebral fractures; 3) new fractures, increased rate of bone loss; 4) intolerant to other bone-active medicaments; 5) antiresorptive therapy ineffective; 6) the treatment of glucocorticoid-induced osteoporosis in men and women. The study EUROFORS in women with previous vertebral fracture reduction is achieved the risk of new vertebral fractures by $65 \%$ and the risk of non-vertebral fractures was reduced by $55 \% .{ }^{49}$

\section{STRONTIUM RANELATE}

Strontium ranelate dissociates to non-radioactive trace element strontium, and ranelic acid that no pharmacological activity and is excreted unchanged by the kidney. ${ }^{1,4,5}$ Evolved strontium affect bone metabolism and improves fracture. ${ }^{5}$ Preclinical studies indicate that Strontium ranelate has a dual mechanism of action: 1) the stimulation of bone formation by: a) synthesis of bone collagen, alkaline phosphatase and osteocalcin; b) contacting a Ca-sensitive receptors that stimulate the mitogen-activated protein kinase enhancing the osteoblast differentiation and proliferation; 2) inhibition of osteoclastogenesis by inhibiting the differentiation, activity and life of osteoclasts; reduction of the expression of RANKL and increased expression in osteoblasts osteoprotegrin. The drug is administered as a first line treatment of postmenopausal women and men with established osteoporosis who are at high risk for fracture. Preventing both vertebral and non-vertebral fractures and hip fractures. Large clinical trials have demonstrated its efficacy in increasing bone mineral density and decreasing fractures in the spine and hip. Performance data from clinical trials are: SOTI, TROPOS, PREVOS, STRATOS. ${ }^{50}$ SOTI study proves that for 3 years strontium ranelate reduces the incidence of new vertebral fractures by $38 \%$ and the occurrence of vertebral and non-vertebral fractures - 32\%. However, European Pharmacovigilance Risk Assessment Committee (PRAC) recommends restriction in the use of strontium ranelate, based on a routine benefit-risk assessment of the medicine, which included data showing an increased risk of heart problems, including heart attacks. ${ }^{50}$ On January 10, 2014 PRAC has recommended that strontium ranelate should no longer be used to treat osteoporosis. ${ }^{50}$

\section{COMBINATION THERAPY OF OSTEOPOROSIS}

Option in the treatment of osteoporosis can be combination of anti-osteoporosis drugs of different classes. After a course of bisphosphonates the therapy could be continued with denosumab, PTH or strontium ranelate. ${ }^{6,7}$ Combination therapy showed greater reduction of fractures than single agent. ${ }^{3}$ The use of a bisphosphonate in association with HRT has additive effects on the reduction of bone resorption markers and BMD. ${ }^{6,39}$ The administration of a bisphosphonate with raloxifene showed greater improvement in BMD ${ }^{39}$ Combination therapy with estrogen and testosteron leads to a significantly higher bone density compared with estrogen monotherapy. ${ }^{45}$ Bazedoxifene (20 $\mathrm{mg} /$ day $)$ in combination with estrogens $(0.625$ $\mathrm{mg} /$ day) enhances bone density of the spine. ${ }^{43}$ It has been shown to reduce the risk of fracture after administration of PTH / teriparatide. ${ }^{49} \mathrm{PTH}$ in combination with an anti-resorptive agent reduces vertebral fractures by $64 \%$ and non-vertebral fractures by $38 \% .{ }^{49}$ 


\section{CONCLUSIONS}

Combination of non-pharmacological and pharmacological treatment options have to be considered for prevention of osteoporosis and minimization of the risk of fractures. Given the heterogeneity of osteoporosis syndrome and lack of significant comparative studies, the choice of a pharmacological agent should be individualized depending on the combination of several factors: 1) the profile of the disease (severity of bone loss and risk factors); 2) the profile of the patient (age, general health, underlying disease); 3) efficiency (types and sizes of anti-fracture effect); 4) tolerance (side effects and contraindications associated); 5) accompanying diseases and contraindications.

\section{ACKNOWLEDGEMENTS}

This paper was prepared with the financial support from Grant Project No 13/2015, Medical University of Plovdiv.

\section{REFERENCES}

1. Sambrook P, Cooper C. Osteoporosis. Lancet 2006; 367 (9527):2010-18.

2. Cheung AM, Detsky AS. Osteoporosis and fractures: missing the bridge. JAMA 2008; 299:1468-70.

3. Becker DJ, Kilgore ML, Morrisey MA. The societal burden of osteoporosis. Curr Rheumatol Rep 2010; 12:186.

4. Pankova S, Vasileva L, Petkova V. A review of current treatment options for osteoporosis in Bulgaria. World Journal of Pharmacy and Pharmaceutical Sciences 2015;4(5):1-12.

5. Sanders S, Geraci SA. Osteoporosis in postmenopausal women: considerations in prevention and treatment: (women's health series). South Med J 2013;106:698-706.

6. Genazzani AR, Gambacciani M, Schneider HPG, Christiansen C. Postmenopausal osteoporosis: therapeutic options. Climacteric 2005;8:99-109.

7. Rachner T, Khosla S, Hofbauer A.Osteoporosis: now and the future. The Lancet 2011;377 (9773):1276-87.

8. Panday K, Gona, A, Humphrey M. Medicationinduced osteoporosis: screening and treatment strategies. Therapeutic Advances in Musculoskeletal Disease 2014;6(5):185-202.

9. Deutschmann HA, Weger M, Weger W. Search for occult secondary osteoporosis: impact of identified possible risk factors on bone mineral density. J Intern Med 2002;252:389-97.

10. Mazziotti G, Canalis E, Giustina A. Drug-induced osteoporosis: mechanisms and clinical Iimplications. Amer J Med 2010;123(10):877-84.
11. van Staa T, Leufkens HG, Abenhain L. Use of oral corticosteroids and risk of fractures. J Bone Miner Res 2000;15:993-1000.

12. Borissova A-M, Rashkov R, Boyanov M, Shinkov A, Popivanov P, Temelkova N, Vlahov J, Gavrailova M. Risk factors for osteoporosis and 10-year absolute fracture risk in a national representative sample of Bulgarian women aged 50 years and older. Endokrinologya 2011;16 (1):4-18 (in Bulgarian).

13. Reginster JY, Burlet N. Osteoporosis: a still increasing prevalence. Bone 2006;38:4-9.

14. Cummings R, Melton J. Epidemiology and outcomes of osteoporotic fractures. Lancet 2002;39:1761-7.

15. Shuit SC, Van Der Klift M, Weel AE. Fracture incidence and association with bone mineral density in elderly men and women: the Rotterdam study. Bone 2004;34:195-202.

16. Waugh EJ, Lam MA, Hawker GA. Risk factors for low bone mass in healthy 40-60 year old women: a systematic review of the literature. Osteoporos Int 2009;20:1-21.

17.Cummings-Vaughn L, Grammack J. Falls, osteoporosis and hip fractures. Med Clin North Amer 2011;95(3):495-506.

18. Cavalli L, Brandi ML. Age- and gender-related macro- and micro-architecture changes in bone structure and implications for treatment. Int J Clin Rheumatol 2011;6:359-69.

19. Coin A, Perissinotto E, Enzi G. Predictors of low bone mineral density in the elderly: role of dietary intake, nutritional status and sarcopenia. Eur J Clin Nutr 2008;23:802-9.

20. Seibel MJ, Robins SP, Bilezikian JP. Dynamics of bone and cartilage metabolism. San Diego: Academic Press; 2006:345-60.

21. Holick MF, Binkley NC, Bischoff-Ferrari HA, Gordon CM, Hanley DA, Heaney RP. Guidelines for preventing and treating vitamin D deficiency and insufficiency revisited. J Clin Endocrinol Metab 2012;97:1153-8.

22.Kanis JA, Johansson H, Johnell O. Alcohol intake as a risk factor for fracture. Osteoporos Int 2005; 16:737-42.

23. Hallstrom H, Wolk A, Glynn A, Michaëlsson K. Coffee, tea and caffeine consumption in relation to osteoporotic fracture risk in a cohort of Swedish women. Osteoporos Int 2006;17(7):1055-64.

24. Kanis JA, Johnell O, Oden O. Smoking and fracture risk: a meta-analysis. Osteoporos Int 2006;16: 155-62.

25. Kasnakova P, Chaushev G, Blazhev D. Sports and physical activity in the prevention of osteoporosis in women working in the Medical College at the Medical University, Plovdiv. Sport y nauka. Special edition. Proceedings of the fifth International Con- 
gress of "Sports, Stress, Adaptation" and "Olympic sports and sports for everyone"; Sofia, 2010:373-4 (Bulgarian).

26. Kasnakova P, Velikov Y. Methodology of complex rehabilitation in cases of disk nemiation. Trakia Journal of Sciences 2012;10 (3):185-7.

27. Kasnakova P, Krushkova P, Kostov S, Slavcheva N. Importance of sports and aerobic exercise for prevention of obesity among children and adolescents. Proceeding book VI International Scientific Congress "Olympic Sport and Sport for All” \& VI International Scientific Congress "Sport, Stress, Adaptation"; 2012 May 17-19; Sofia. p. 479-81.

28. Krushkova P., Kasnakova P. The role of sports and physical activity in the complex therapy for diabetes treatment. Proceeding book VI International Scientific Congress "Olympic Sport and Sport for All” \& VI International Scientific Congress "Sport, Stress, Adaptation"; 2012 May 17-19; Sofia. p. 481-4.

29. Raisz LG. Pathogenesis of osteoporosis: concepts, conflicts, and prospects. J Clin Invest 2005;115: 3318-25.

30. Gallagher J. Advances in bone biology and new treatments for bone loss. Maturitas 2008;60(1):65-9.

31. Lewiecki EM, Watts NE, McClung MR.World Health Organization (WHO) Assessment of fracture risk and application to screening for postmenopausal osteoporosis report of a WHO study group WHO technical report series n 843 WHO Geneve Suisse 19941-29 Official position of the International society for chnical densitometry J Clin Endocnnol Metab 2004;89:3651-5.

32. Kanis JA. Diagnosis of osteoporosis and assessment of fracture risk. Lancet 2002;359:1929-36.

33. Tremollieres M., Ribot K. Bone mineral density and prediction of non-osteoporotic disease. Maturitas 2010;65(4):348-51.

34. Mu H, Bai YH, Wang ST, Zhu ZM, Zhang YW. Research on antioxidant effects and estrogenic effect of Formononetin from Trifolium pratense (red clover). Phytomedicine 2009;16(4):314-9.

35. Tang BM, Eslick GD, Newson C. Use of calcium or calcium in combination with vitamin $\mathrm{D}$ supplementation to prevent fractures and bone loss in people aged 50 years and older a meta analyse. Lancet 2007;370:657-66.

36. Mithal A, Wahl DA, Bonjour J. Global vitamin D status and determinants of hypovitaminosis D. Osteoporos Int 2009;20(11):1807-20.
37. Bikle D. Vitamin D and bone. Curr Osteoporos Rep 2012;10(2):151-9.

38. Russell R. Bisphosphonates: from bench to bedside. Ann N Y Acad Sci 2006;1068:367-401.

39. Kimmel B. Mechanism of action, pharmacokinetics and pharmacodynamic profile, and clinical application of nitrogen containing bisphosphonates. J Dent Res 2007;86(11):1022-33.

40.van Beek E, Cohen L, Leroy I, Ebetino F, Löwik C, Papapoulos S. Differentiating the mechanisms of antiresorptive action of nitrogen containing bisphosphonates. Bone 2003;33(5):805-11.

41. Cummings SR, San Martin J, McClung MR. FREEDOM Trial. Denosumab for prevention of fractures in postmenopausal women with osteoporosis. N Engl J Med 2009;361:756-65.

42. Krassas GE, Papadopoulou P. Oestrogen action on bone cells. J Musculoskelet Neuronal Interact 2001;2(2):143-51.

43. Cauley JA, Robbins J, Chen Z. Women's Health Initiative (WHI) investigators. Effects of estrogen plus progestin on risk of fracture and bone mineral density: the Women's Health Initiative randomised trial. JAMA 2003;290:1729-38.

44. Ascott-Evans B, Sonnendecker E, De Villiers T. Hormone therapy in postmenopausal osteoporosis. JEMDSA 2008;13:8-12.

45. Tuck SP, Francis RM. Testosterone, bone and osteoporosis. Front Horm Res 2009;37:123-32.

46. Chesnut CH, Silverman S, Andriano K. A randomised trial of nasal spray salmon calcitonin in postmenopausal women with established osteoporosis: the PROOF study. Am J Med 2000;109:267-76.

47. Rey JRC, Cervino EV, Rentero ML. Raloxifene: mechanism of action, effects on bone tissue, and applicability in clinical traumatology practice. Open Orthop J 2009;3:14-21.

48. Sacco SM, Horcajada MN, Offord E. Phytonutrients for bone health during ageing. Br J Clin Pharmacol 2013;75(3):697-707.

49. Cranney A, Papaioannou A, Zytaruk N. Parathyroid hormone for the treatment of osteoporosis: a systematic review. CMAJ 2006;175:52-9.

50. European Medicines Agency. PRAC recommends suspending use of Protelos / Osseor (strontium ranelate) Recommendation by PRAC to be considered by CHMP for final opinion. Press release 10 January 2014; p.1-2. 